its catalyst remains constant so that machines have been in constant satisfactory operation for many weeks at a time. Being very nearly instantaneous these methods are particularly useful for continuous analysis of a changing gas mixture. Attempts to apply them to the analysis of flue and combustion gases are already under way.

WashingtoN, D. C.

[CONTRIBUTION FROM THE KENT ChEMICAL LABORATORY OF THE UNIVERSITY OF Chicago.]

\title{
STUDIES IN CONDUCTIVITY. VI. THE BEHAVIOR OF MIX- TURES OF TWO SALTS CONTAINING A COMMON ION IN ANHYDROUS FORMIC ACID SOLUTION.
}

By H. I. SCHLESTNGeR aNd F. H. REED. ${ }^{3}$

Received July 28, 1919.

The first 4 papers of this series ${ }^{2}$ have dealt with the agreement of solutions of formates in anhydrous formic acid with the demands of the law of mass action, when the degree of ionization is determined by the conductivity method, although in such solutions these electrolytes are very highly ionized. Since highly ionized substances in other solvents do not obey this law, there exist at present no measurements for strong electrolytes which can be used to verify the deductions which are made from the law for the behavior of mixtures of two electrolytes with a common ion. An investigation of such mixtures therefore seemed desirable, especially as agreement with the law in the behavior of the mixtures, as well as of the individual salts, would dispose of the possibility that the agreement in the case of the latter is due to any accidental cancellation of deviations. ${ }^{3}$ This study, in addition to having fulfilled the purposes just mentioned, has resulted in bringing out some points that may lead to a better understanding of concentrated solutions and has thrown further light on the peculiar behavior of the formates of the alkaline earths.

In most details the methods of Schlesinger and Martin were followed without change except for the following points: The formic acid was prepared by distilling Bake \& Adamson's acid, prepared especially for our work, from $1 / 10$ its volume of phosphorus pentoxide at $20^{\circ}$ to $27^{\circ}$, and a pressure of Io to $I 8 \mathrm{~mm}$. Three distillations, in the apparatus already described, usually produced an acid with a specific conductivity

1 The work reported in this and the preceding paper of this series has been presented to the Faculty of the Ogden Graduate School of Science of the University of Chicago by F. H. Reed in partial fulfillment of the requirements for the degree of Doctor of Philosophy. The work was completed in June, 1917.

${ }^{2}$ Schlesinger and collaborators as follows: With Calvert, THIs JourNal, 33, I924 (I9II); with Martin, Ibid., 36, I589 (I9I4); with Coleman, Ibid., 38, 27 (Igr6); with Mullinix, Ibid., 4I, 72 (1919).

'See also the seventh paper of the series which follows. 
of about $6.5 \times 10^{-5}$ reciprocal ohms. The formates were made as by Schlesinger and Coleman; they were recrystallized from absolute alcohol until their conductivities in solution were unchanged by further recrystallization. The formates of strontium and calcium used were parts of the samples prepared by Schlesinger and Mullinix. All salts were analyzed by conversion into sulfates and were found pure within the limits of the analytical method. All solutions were made by weighing the salt directly into the $25 \mathrm{cc}$. volumetric flasks. Weights were corrected to vacuum. The conductivities were measured by the Washburn modification of the Wheatstone-Kohlrausch method with the special precautions, the necessity for which was pointed out in the fifth paper of this series. ${ }^{1}$

\section{Ionization Constants.}

For the interpretation of our work on the mixed solutions an accurate knowledge of the ionization constants of the salts investigated is necessary. When these constants were taken from the earlier work of this series, for which an accuracy of from 0.2 to $0.3 \%$ was quite sufficient, it was found that the calculated results showed certain irregularities which we ascribed to very slight errors in the relative values of the various ionization constants employed. Since our improved apparatus and methods, described in the paper referred to above, enabled us to determine the conductivities of solutions with a maximum average error of slightly less than $0.05 \%$, it was deemed advisable to redetermine these constants. Tables I, II and III show the results obtained. In each case no more determinations were made than were needed to cover a sufficient range of concentration to make dependable the average value of the ionization constant of that salt. In the first column of each of these tables is given the concentration of each of the respective salts expressed in gram mols

Table I.-The Conductivity of Potassium Formate Solution at $25^{\circ}$ IN Anhydrous Formic Acid.

\begin{tabular}{|c|c|c|c|c|c|c|}
\hline $\begin{array}{c}\text { Cone. } \\
\text { o }\end{array}$ & $\mathrm{x}$. & $\begin{array}{c}\mathrm{x}_{a} \\
\ldots\end{array}$ & $\begin{array}{c}\lambda a . \\
68.92\end{array}$ & $\alpha$ & $\begin{array}{l}K \\
\ldots\end{array}$ & $\begin{array}{c}\text { \% error } \\
\ldots\end{array}$ \\
\hline 0.1027 & $0.00658 \mathrm{I}$ & 0.006516 & 63.43 & 0.920 & 1.092 & 0.01 \\
\hline 0.1314 & 0.008232 & 0.008167 & 62.18 & 0.902 & I. .092 & 0.02 \\
\hline 0.1804 & 0.01093 & 0.01086 & 60.22 & 0.874 & 1.091 & 0.01 \\
\hline 0.1992 & 0.01193 & 0.01187 & 59.35 & 0.864 & 1.095 & 0.06 \\
\hline 0.2312 & 0.01356 & 0.01350 & 58.39 & 0.847 & I. 086 & 0.05 \\
\hline 0.2433 & 0.01418 & $0.014 \mathrm{II}$ & 57.99 & $0.84 \mathrm{I}$ & 1.087 & 0.04 \\
\hline 0.2696 & 0.01549 & 0.01543 & 57.24 & $0.83 \mathrm{I}$ & 1.097 & 0.09 \\
\hline 0.2792 & 0.01595 & 0.01589 & 56.90 & 0.826 & I. $.09 \mathrm{I}$ & 0.02 \\
\hline 0.3104 & 0.01744 & 0.01738 & 55.99 & 0.812 & I. 092 & 0.03 \\
\hline 0.3232 & 0.01802 & 0.01796 & $55 \cdot 5^{8}$ & 0.806 & 1,085 & 0.06 \\
\hline 0.3253 & 0.01813 & 0.01806 & $55 \cdot 52$ & 0.806 & 1.086 & 0.06 \\
\hline 0.3266 & 0.01818 & 0.01812 & $55 \cdot 48$ & 0.805 & I .085 & 0.07 \\
\hline
\end{tabular}


Table II.-The Conductivity of Sodium Formate Solution at $25^{\circ}$ IN

\begin{tabular}{ccccccc} 
Conc. & $\boldsymbol{7}$. & ANHYDROUS FORMIC ACID. \\
\multicolumn{1}{c}{$\mathbf{x}$} & $\ldots \ldots$ & $\ldots \ldots$ & 66.225 & $\ldots$ & $\ldots$. & $\%$ error \\
0.06418 & 0.004025 & 0.003960 & 61.70 & 0.932 & 0.815 & 0.04 \\
0.06881 & 0.004289 & 0.004225 & 61.39 & 0.927 & 0.810 & 0.00 \\
0.08375 & 0.005135 & 0.005071 & 60.54 & 0.914 & 0.816 & 0.06 \\
0.09682 & 0.005850 & 0.005786 & 59.75 & 0.902 & 0.807 & 0.04 \\
0.1755 & 0.009888 & 0.009820 & 55.94 & 0.845 & 0.806 & 0.06 \\
0.2068 & 0.01137 & 0.01131 & 54.67 & 0.826 & 0.808 & 0.03 \\
0.2337 & 0.01262 & 0.01256 & 53.72 & 0.811 & 0.814 & 0.04 \\
0.2528 & 0.01346 & 0.01340 & 53.00 & 0.800 & 0.810 & 0.01 \\
0.2734 & 0.01436 & 0.01429 & 52.28 & 0.789 & 0.809 & 0.02 \\
0.2954 & 0.01529 & 0.01522 & 51.54 & 0.778 & 0.807 & 0.07 \\
0.3153 & 0.01613 & 0.01606 & 50.94 & 0.769 & 0.808 & 0.05
\end{tabular}

per liter of solution; in Col. 2 the specific conductivity (X) at $25^{\circ} \pm$ $0 . \mathrm{or}^{\circ}$, in reciprocal ohms; in Col. 3 the specific conductivity $\left(\mathrm{X}_{\varepsilon}\right)$ corrected for the conductivity of the solvent; in Col. 4 the equivalent conductivity $\left(\lambda_{a}\right)$ calculated from the corrected specific conductivity; in Col. 5 the degree of ionization $(\alpha)$ the necessary $\lambda_{0}$ being found as described in the earlier papers of this series; in Col. 6 the ionization constant $(K)$ as calculated from the equation $\alpha^{2} C /(\mathbf{I}-\alpha)=K$; in Col. 7 the percentage error in the measured specific conductivity which would account for the deviation of the individual values of $K$ from

Table III.-The Conductivity of Lithium Formate Solution at $25^{\circ}$ IN ANHYDROUS Formic AcID.

$\begin{array}{lcccccc}\text { Conc. } & \mathbf{X} . & \mathbf{x}_{a} . & \boldsymbol{\lambda}_{a} & \boldsymbol{\alpha} . & \boldsymbol{K} . & \% \text { error. } \\ 0 & \ldots \ldots & \ldots \ldots & 64.72 & \ldots & \ldots & \ldots \\ 0.06709 & 0.003978 & 0.003917 & 58.38 & 0.902 & 0.557 & 0.01 \\ 0.09025 & 0.005180 & 0.005116 & 56.68 & 0.876 & 0.557 & 0.00 \\ 0.1018 & 0.005752 & 0.005689 & 55.86 & 0.863 & 0.554 & 0.06 \\ 0.1248 & 0.006861 & 0.006797 & 54.46 & 0.841 & 0.557 & 0.01 \\ 0.1438 & 0.007737 & 0.007673 & 53.37 & 0.825 & 0.557 & 0.01 \\ 0.1524 & 0.008122 & 0.008061 & 52.90 & 0.817 & 0.557 & 0.01 \\ 0.1658 & 0.008722 & 0.008658 & 52.21 & 0.807 & 0.558 & 0.02 \\ 0.1749 & 0.009116 & 0.009053 & 51.77 & 0.800 & 0.559 & 0.06 \\ 0.1750 & 0.009114 & 0.009053 & 51.73 & 0.799 & 0.557 & 0.00 \\ 0.1915 & 0.009811 & 0.009750 & 50.92 & 0.787 & 0.556 & 0.03 \\ 0.1916 & 0.009835 & 0.009773 & 50.95 & 0.787 & 0.559 & 0.06 \\ 0.2044 & 0.01036 & 0.01030 & 50.38 & 0.778 & 0.559 & 0.06 \\ 0.2196 & 0.01099 & 0.01092 & 49.73 & 0.768 & 0.559 & 0.07 \\ 0.2480 & 0.01209 & 0.01203 & 48.51 & 0.750 & 0.556 & 0.03 \\ 0.2596 & 0.01253 & 0.01247 & 48.01 & 0.742 & 0.553] & 0.16 \\ 0.3076 & 0.01429 & 0.01423 & 46.24 & 0.714 & {[0.550]} & 0.30 \\ & & & & & \text { Av. }{ }^{a} 0.557 & \end{array}$

a The bracketed values were not used in obtaining the average because they were obtained from solutions so concentrated that the mass law is no longer obeyed. 
the average value. This percentage error is given because relatively large deviations in the constant may be due to very small errors in the conductivity, which is the measured quantity showing the net experimental error. It will be seen that in every case this error is less than $0, x \%$, and is in nearly all cases very much less.

\section{Method of Calculation.}

By the use of the constants thus determined a method for the calculation of the specific conductivity of a solution of a mixture of any two of these salts (e. g., sodium and potassium formates) was developed as follows: The specific conductivity $\left(\mathrm{X}_{m}\right)$ of such a mixture is considered the sum of the specific conductivity $\left(\mathrm{X}_{1}\right)$ of the first salt (sodium formate), and of the specific conductivity $\left(\mathrm{X}_{2}\right)$ of the second salt (potassium formate); or, $\mathrm{X}_{m}=\mathrm{X}_{1}+\mathrm{X}_{2}$. Now, in general, if $\lambda$ represents the equivalent conductivity, $\mathrm{X}$ the specific conductivity, $\alpha$ the degree of ionization, and $C$ the concentration, the relation holds that rooo $\mathrm{X} / C=\lambda=\alpha \lambda_{0}$, where $\lambda_{0}$ is the equivalent conductivity at infinite dilution; or it may be written in the form

\section{Consequently,}

$$
\operatorname{rooo} \mathbf{X}=\alpha \lambda_{\circ} C \text {. }
$$

$$
1000 \mathrm{X}_{m}=\alpha_{1} \lambda^{\prime}{ }_{\circ} C_{1}+\alpha_{2} \lambda^{\prime \prime}{ }_{\circ} C_{2},
$$

in the right hand member of which equation the first term gives the specific conductivity of one of the salts, and the second term that of the other salt. ${ }^{1}$ It may be noted that the only unknown terms in this equation are the respective degrees of ionization of the two salts. If it is assumed for the present that one of these, $\alpha_{2}$, is known (the method of finding it will be discussed later), it is possible to find an expression for $\alpha_{1}$ in terms of $\alpha_{2}$ and other known quantities as follows:

Upon the basis of the assumption that the law of chemical equilibrium is obeyed when these two salts containing a common ion are present together in a solution, the ionization constants $K_{1}$ and $K_{2}$ may be expressed thus, respectively:

$$
\begin{aligned}
& \alpha_{1}\left(\alpha_{1} C_{1}+\alpha_{2} C_{2}\right) /\left(\mathbf{I}-\alpha_{1}\right)=K_{1}, \\
& \alpha_{2}\left(\alpha_{1} C_{1}+\alpha_{2} C_{2}\right) /\left(\mathbf{I}-\alpha_{2}\right)=K_{2},
\end{aligned}
$$

from which, dividing ( 2 ) by (3), we obtain:

$$
\alpha_{1}=\frac{\alpha_{2} K_{1} / K_{2}}{\mathrm{I}-\alpha_{2}\left(\mathrm{I}-K_{1} / K_{2}\right)}
$$

Since $K_{1}$ and $K_{2}$ are known for the salts in question, Equation 4 makes the calculation of $\alpha_{1}$. very simple when $\alpha_{2}$ is known.

Equation 3 may be written

$$
\alpha_{1} C_{1}+\alpha_{2} C_{2}=K_{2}\left(\mathrm{I}-\alpha_{2}\right) / \alpha_{2} .
$$

1 Terms with subscript $x$ refer in general to one of the salts; terms with subscript 2 to the other. 
Dividing by $\alpha_{2}$ we obtain

$$
C_{2}+C_{1} \alpha_{1} / \alpha_{2}=K_{2}\left(\mathrm{I}-\alpha_{2}\right) / \alpha_{2}{ }^{2} .
$$

The law of mass action reads

$$
\alpha_{2}{ }^{2} C /\left(\mathrm{I}-\alpha_{2}\right)=K_{2} \text {, or } C=K_{2}\left(\mathrm{I}-\alpha_{2}\right) / \alpha_{2}{ }^{2} .
$$

Now it is self evident that $C$ in Equation 6 represents a concentration of the second salt, in a solution containing that salt only, in which the degree of ionization, $\alpha_{2}$, is the same as it is in the mixture of the two salts for which Equation 5 holds. Calling this concentration $C_{s}$, we may rewrite Equation 5

$$
C_{2}+C_{1} \alpha_{1} / \alpha_{2}=C_{s}
$$

In order to use the equations just given, we now calculate for a series of arbitrarily chosen values of $\alpha_{2}$ the corresponding values of $\alpha_{1}$ and $C_{s}$ by use of Equations 4 and 6, and plot $\alpha_{1} / \alpha_{2}$ against either $C_{s}$ or $\alpha_{2} \cdot{ }^{1}$ The first step in the calculation is to chose a value for $C_{s}$ which might be the one in which the ionization of the second salt in a solution of that salt only is the same as it is in the mixture for which the calculation is to be made. In order to test the correctness of this value, we read off from the plot the value of $\alpha_{1} / \alpha_{2}$, corresponding to that of $C_{s}$ which has been chosen, and from the known values of $C_{1}$ and $C_{2}$ calculate the numerical value of the expression $C_{2}+C_{1} \alpha_{1} / \alpha_{2}$. If this is equal to $C_{s}$, as demanded by Equation 7, the value chosen for $C_{s}$ is correct; if it is not, we must choose another value for $C_{s}$ and continue by a method of trial until the correct value is obtained.

This method of calculation may be illustrated in the case of Expt. I4, Table V. The sum of the concentrations of the two salts is about 0.219 . Since this is not all potassium formate it is clear that a solution of this salt alone in which the concentration is somewhat less than 0.219 would be ionized to the same extent as the potassium formate in the mixture. ${ }^{2}$ We therefore assume for $C_{s}$, the value 0.21 ; from the curve, the corresponding value of $\alpha_{1} / \alpha_{2}$ is 0.9532 . Now $C_{2}$ and $C_{1}$ in this experiment were, respectively, 0.05699 and 0.1622 , whence $C_{2}+C_{1} \alpha_{1} / \alpha_{2}=0.2116$, a value of $C_{s}$ different from that assumed. Since $\alpha_{1} / \alpha_{2}$ decreases as $C_{s}$ increases, it is evident that a higher value of $C_{s}$ must be assumed; finally assuming the value 0.2115 for $C_{s}$, the corresponding $\alpha_{1} / \alpha_{2}$ is 0.953 and $C_{2}+C_{1} \alpha_{1} / \alpha_{2}=0.21156$, which is sufficiently close to 0.2115 to be considered identical. From the second plot and the value 0.953 for $\alpha_{1} / \alpha_{2}$, we now find that $\alpha_{2}$ is $0.857,{ }^{3}$ whence $\alpha_{1}$ is $0.8 \mathrm{I} 67$. We can now use these

${ }^{1}$ Other combinations could be used for these plots, but the two mentioned are the most convenient.

${ }^{2}$ Note that for $C_{S}$ we always use the data for the salt of greater ionization which is the second salt of the mixtures.

${ }^{3}$ From the value 0.2 I $5_{5}$ for $C_{s}$ and Equation 6 the value of $\alpha_{2}$ might be calculated but the use of the second curve is simpler. 
values in testing the experimental data. If both salts in the mixture obey the mass law and if the equivalent conductances of none of the ions is affected by the other ions or molecules present, the specific conductivity of the mixture should, according to Equation I, be 0.01214 , whereas experiment gave 0.012 I 5 .

This method of calculation ${ }^{1}$ has proved quite simple and accurate. All curves were plotted to such scale that the conductivities of the mixed solutions could be calculated with an accuracy as great as that of the measurements.

When $C_{1}=C_{2}$, as is true of a number of the experiments, the calculation can be somewhat simplified, as in this case Equation 2 becomes

$$
C=K_{1}\left(\mathrm{I}-\alpha_{1}\right) / \alpha_{1}\left(\alpha_{1}+\alpha_{2}\right) \text {. }
$$

Table IV contains the data used in constructing the curves for the calculation of the conductivity of mixed solutions. It will be understood from the foregoing discussion that these data are derived from the ionization constants given in the preceding section of this paper and from those given by Schlesinger and Mullinix ${ }^{2}$ in the case of the alkaline earth formates and therefore are in no way dependent on the values found for the conductivities of the mixed solutions. 'The first column contains the values for $\alpha_{2}$, which are arbitrarily chosen at uniform intervals and which in the mixture of potassium formate with sodium, with lithium and with strontium formate, refer to the degree of ionization of the potassium salt. For the mixtures of strontium formate with calcium formate, $\alpha_{2}$ refers to the degree of ionization of strontium formate. The next 5 columns show the corresponding degree of ionization of the other salts, as calculated by Equation 4. In order to make clear to what mixture each set of data refers, the symbols $\alpha_{1, \mathrm{Na}}, \alpha_{1, \mathrm{Li}}, \alpha_{1, \mathrm{Sr}}, \alpha_{1}, \mathrm{Ca}$ have been used. It will be noted that two sets of values of $\alpha_{1, S r}$, the degree of ionization of strontium formate, corresponding to the values for potassium formate given in the first column, are to be found in Cols. 4 and 5 ; the significance of this will be explained later. Attention may be called to the fact that values of $\alpha_{1}$ and of $C_{s}$, corresponding to those of $\alpha_{2}$, have not been given in all cases-only those values required for the calculations have been included in the table. Col. 7 gives the value $C_{K}$, which is identical with $C_{s}$ of Equation 7 when potassium formate is the second salt of the mixture and Col. 8, the value of $C_{S r}$, which is the same as $C_{s}$ when the second salt of the mixture is strontium formate. ${ }^{3}$

${ }^{1}$ Calculations of this sort have been made in aqueous solutions by the isohydric principle. When the mass law is supposed to be obeyed, the isohydric principle in the simple form is applicable only to those cases in which the ionization constants are very small-a point which is sometimes overlooked.

2 Loc cit.

${ }^{3}$ In the mixtures of strontium and potassium formate the latter is considered the second salt. 
Table IV.-Data for the Calculation of the Conductivities of Solutions AND Mixtures. ${ }^{.}$

\begin{tabular}{|c|c|c|c|c|c|c|c|}
\hline$\alpha_{2}$ & $\alpha_{1, \mathrm{Na}}$ & $\alpha_{1, L i}$ & $\alpha_{1, S r}^{\prime}$ & $\alpha n_{1, S r}$ & $\alpha_{1}, \mathrm{Ca}$ & $c_{K}$ & $c_{\mathrm{Sr}}$ \\
\hline 0.670 & & $\ldots$ & $\ldots$ & $\ldots$ & 0.6255 & $\ldots$ & 0.3767 \\
\hline 0.680 & $\ldots$ & $\ldots$ & $\ldots$ & $\ldots$ & $0.636 \mathrm{I}$ & $\ldots$ & 0.3554 \\
\hline 0.690 & $\ldots$ & $\ldots$ & $\ldots$ & $\ldots$ & 0.6468 & $\ldots$ & 0.3344 \\
\hline 0.700 & $\ldots$ & $\ldots$ & $\ldots$ & $\ldots$ & 0.6575 & $\ldots$ & 0.3144 \\
\hline 0.710 & $\ldots$ & $\ldots$ & $\ldots$ & $\ldots$ & 0.6682 & $\ldots$ & 0.2955 \\
\hline 0.720 & $\ldots$ & $\ldots$ & $\ldots$ & $\ldots$ & 0.6790 & $\ldots$ & 0.2774 \\
\hline 0.730 & $\ldots$ & $\ldots$ & $\ldots$ & $\ldots$ & 0.6898 & $\ldots$ & 0.2602 \\
\hline 0.740 & $\ldots$ & $\ldots$ & $\ldots$ & $\ldots$ & 0.7007 & $\ldots$ & 0.2439 \\
\hline $0.75^{\circ}$ & $\ldots$ & 0.6052 & $\ldots$ & $\ldots$ & 0.7116 & 0.4845 & 0.2283 \\
\hline 0.760 & $\ldots$ & 0.6180 & $\ldots$ & $\ldots$ & 0.7226 & 0.4529 & $0.2 \times 34$ \\
\hline 0.770 & $\ldots$ & 0.6311 & $\ldots$ & $\ldots$ & 0.7336 & 0.4227 & 0.1992 \\
\hline 0.780 & $\ldots$ & 0.6443 & $\ldots$ & $\ldots$ & 0.7448 & 0.3942 & 0.1857 \\
\hline 0.790 & 0.7365 & 0.6578 & $\ldots$ & 0.6393 & 0.7558 & 0.3667 & 0.1728 \\
\hline 0.800 & 0.7483 & 0.6715 & $\ldots$ & 0.6534 & 0.7669 & 0.3406 & 0.1605 \\
\hline 0,810 & 0.7601 & 0.6854 & $\ldots$ & 0.6677 & $0.778 \mathrm{I}$ & 0.3156 & 0.1487 \\
\hline 0.820 & 0.7720 & 0.6995 & $\ldots$ & 0.6822 & 0.7894 & 0.29 I 8 & o.1 375 \\
\hline 0.830 & 0.7839 & 0.7139 & 0.5349 & 0.6970 & 0.8006 & 0.2690 & 0.1267 \\
\hline $0.84^{\circ}$ & 0.7960 & 0.7285 & 0.5530 & 0.7121 & $\ldots$ & 0.2472 & $\ldots$ \\
\hline 0.850 & $0.808 \mathrm{I}$ & 0.7433 & 0.5718 & 0.7275 & $\ldots$ & 0.2263 & $\ldots$ \\
\hline 0.860 & 0.8203 & 0.7584 & 0.5914 & 0.7432 & $\ldots$ & 0.2063 & . \\
\hline 0.870 & 0.8326 & 0.7737 & 0.6 II & 0.7593 & $\ldots$ & 0.1872 & $\ldots$ \\
\hline 0.880 & 0.8449 & 0.7893 & 0.6334 & 0.7755 & $\ldots$ & 0.1689 & $\ldots$ \\
\hline 0.890 & 0.8574 & $\ldots$ & 0.6559 & 0.7922 & $\ldots$ & 0,1514 & $\ldots$ \\
\hline 0.900 & 0.8699 & $\ldots$ & 0.6795 & 0.8092 & $\ldots$ & 0.1346 & \\
\hline 0.910 & 0.8826 & $\ldots$ & 0.7043 & 0.8265 & $\ldots$ & 0.1184 & \\
\hline 0.920 & 0.8953 & $\ldots$ & 0.7304 & $\ldots$ & $\ldots$ & 0.1030 & $\ldots$ \\
\hline 0.930 & $\ldots$ & $\ldots$ & $0.757^{8}$ & $\ldots$ & $\ldots$ & 0.0882 & \\
\hline
\end{tabular}

a The ionization constants used in the calculation of the data in this table are I.09, $0.810,0.557,0.514$ and 0.422 for potassium, sodium, lithium, strontium and calcium formates, respectively. The first 3 values are taken from the first section of this paper; the others from the work of Schlesinger and Mullinix (loc. cit.). The values given in that paper are slightly different from those used here. This is due to the fact that the work herein reported was completed before that of Mullinix and consequently we used his preliminary values for the constants and the conductivity at zero concentration of the two alkaline earth formates. A recalculation of a few of the data with the final values has shown that no change of importance is introduced into the results or conclusions and as the calculations require a great deal of time they have not been repeated.

\section{Solutions Containing a Mixture of Two Uni-univalent Salts.}

Table $\mathrm{V}$ gives the results of the work done with solutions of mixtures of sodium and potassium formates. The first column of the table gives the number of the experiment since this information is required for later reference, and Col. 9 shows the percentage deviation between the specific conductivities Col. 7 , calculated on the assumption that the mass law holds in the solutions of the mixtures for both salts by the method just disctussed, and the experimentally determined specific con- 
ductivities Col. 8. The meanings of the headings of the other columns have already been given.

TABLE V.-THE CONDUCTIVITY OF SOLUTIONS OF MIXTURES OF SODIUM AND Potasstum Formates in ANHYdrous Formic ACID aT $25^{\circ}$.

$\begin{array}{rcccccccc}\text { Expt. } & C_{5} . & C_{1 .} & C_{2} & \alpha_{1 .} & \alpha_{2 .} & \text { X calc. } & \text { X found. \% error. } \\ 8 & \ldots & 0.05288 & 0.05288 & 0.894 & 0.919 & 0.006481 & 0.006492 & 0.17 \\ 9 & \ldots & 0.05306 & 0.05306 & 0.894 & 0.919 & 0.006500 & 0.006512 & 0.19 \\ \text { I0 } & \ldots & 0.06197 & 0.06197 & 0.880 & 0.908 & 0.007488 & 0.007486 & 0.02 \\ 4 & \ldots \ldots & 0.07113 & 0.07114 & 0.866 & 0.897 & 0.008475 & 0.008478 & 0.03 \\ 2 & \ldots & 0.08755 & 0.08755 & 0.843 & 0.879 & 0.01019 & 0.010195 & 0.06 \\ 5 & \ldots & 0.1014 & 0.1014 & 0.825 & 0.864 & 0.01158 & 0.01159 & 0.10 \\ \text { II } & 0.2025 & 0.1081 & 0.09941 & 0.823 & 0.862 & 0.01179 & 0.01178 & 0.13 \\ \text { I4 } & 0.2115 & 0.1622 & 0.05699 & 0.817 & 0.857 & 0.01214 & 0.01215 & 0.03 \\ 7 & \ldots & 0.1076 & 0.1076 & 0.818 & 0.858 & 0.01219 & 0.01219 & 0.02 \\ \text { I2 } & 0.2188 & 0.08522 & 0.1377 & 0.812 & 0.853 & 0.01268 & 0.01269 & 0.06 \\ \text { I3 } & 0.2381 & 0.1493 & 0.09645 & 0.801 & 0.844 & 0.01353 & 0.01351 & 0.22 \\ 3 & \ldots \ldots & 0.1231 & 0.1231 & 0.800 & 0.843 & 0.01367 & 0.01369 & 0.12 \\ 6 & \ldots & 0.1304 & 0.1304 & 0.792 & 0.837 & 0.01436 & 0.01440 & 0.24 \\ \text { I6 } & 0.2645 & 0.1344 & 0.1375 & 0.786 & 0.832 & 0.01489 & 0.01491 & 0.15 \\ \text { I } & \ldots \ldots & 0.1476 & 0.1476 & 0.775 & 0.822 & 0.01593 & 0.01592 & 0.06 \\ \text { I5 } & \ldots \ldots & 0.1628 & 0.1628 & 0.761 & 0.810 & 0.01729 & 0.01728 & 0.05 \\ \text { I7 } & \ldots \ldots & 0.1867 & 0.1867 & 0.739 & 0.792 & 0.01933 & 0.01929 & 0.22\end{array}$

Similar measurements and calculations made for solutions of mixtures of lithium and potassium formates are presented in Table VI. It is of interest to note that the mixtures of sodium and potassium formates represent a case in which the ionization constants of the two salts (0.810 and I.09, respectively) do not differ very greatly, while for the mixtures of lithium and potassium formates the difference in the constants $(0.557$ and $I .09$, respectively) is much greater.

Table VI.-The Conductivity of Solutions of Mixtures of Lithium. and Potassium Formates in ANhydrous Formic Acid at $25^{\circ}$.

\begin{tabular}{|c|c|c|c|c|c|c|c|c|}
\hline $\begin{array}{c}\text { Expt. } \\
2\end{array}$ & $\begin{array}{c}C_{s} \\
\ldots\end{array}$ & $\begin{array}{c}C_{1} \\
0.08933\end{array}$ & $\begin{array}{c}C_{2} \\
0.08932\end{array}$ & $\begin{array}{c}\alpha_{1} . \\
0.789\end{array}$ & $\begin{array}{c}\alpha_{2} . \\
0.880\end{array}$ & $\begin{array}{c}x \text { calc. } \\
0.009976\end{array}$ & $\begin{array}{l}\text { X found. } \\
0.009981\end{array}$ & $\begin{array}{r}\text { \% error } \\
0.02\end{array}$ \\
\hline 6 & 0.1821 & 0.1216 & 0.07373 & 0.778 & 0.873 & 0.01056 & 0.01056 & 0.01 \\
\hline 7 & $\ldots$ & 0.1082 & 0.1082 & $0.76 \mathrm{I}$ & 0.862 & $0.01 I 75$ & o, OII 74 & 0.04 \\
\hline 3 & $\ldots$ & O.II59 & 0.1159 & 0.750 & 0.854 & 0.01244 & 0.01244 & 0.02 \\
\hline 8 & $\ldots$ & 0.1219 & 0.1219 & 0.742 & 0.849 & 0.01298 & 0.01299 & 0.06 \\
\hline 4 & $0.240 \mathrm{r}$ & $0.223 \mathrm{I}$ & 0.04618 & 0.733 & 0.843 & 0.01327 & 0.01326 & 0.05 \\
\hline 5 & 0.2348 & $0.0751 \mathrm{I}$ & 0.1694 & 0.737 & 0.846 & 0.01346 & 0.01346 & 0.0 \\
\hline I & $\ldots$ & 0.1374 & 0.1374 & 0.722 & 0.836 & 0,01434 & 0.01434 & 0.0 \\
\hline 9 & $0.280 \mathrm{I}$ & 0.1618 & $0.1+15$ & 0.707 & 0.825 & o. OI 545 & 0.01544 & 0.0 \\
\hline I 3 & $0.263 I$ & $0.224 \mathrm{I}$ & 0.06986 & 0.718 & 0.833 & $0.0144^{2}$ & 0.01439 & 0.3 \\
\hline II & 0.2860 & 0.2266 & 0.09227 & 0.703 & 0.822 & 0.01554 & 0.01549 & 0.3 \\
\hline$I_{4}$ & $0.3 I 24$ & 0.2002 & 0.1428 & 0.687 & $0.8 \mathrm{II}$ & 0.01689 & $0.0168 \mathrm{I}$ & 0.4 \\
\hline I2 & $0.327 \mathrm{I}$ & 0.2233 & o. 1388 & 0.679 & 0.805 & 0.01752 & 0.01741 & 0.6 \\
\hline
\end{tabular}

It will be seen from Table $\mathrm{V}$ that the experimentally determined conductivity of solutions containing both sodium and potassium formates agrees extremely well with the value calculated on the assumption that 
the mass law is applicable in these mixtures. The maximum deviation is $0.24 \%$, which can easily be accounted for by errors less than $0.1 \%$ in the conductivity measurements on which the values of the ionization constants of the two salts were based. The mixtures of lithium and potassium formates show an even better agreement as inspection of the first 9 lines of Table VI shows, the maximum deviation being only $0.06 \%$. This result may be taken as fairly definite proof that the agreement between the demands of the mass law and the actual behavior of the uniunivalent formates in anhydrous formic acid solutions is a real and not merely an apparent one.

The last 4 measurements shown in Table VI require further discussion. It has been shown in an earlier paper ${ }^{1}$ of this series that the agreement between the mass law and the behavior of the alkali formate solutions ceases when fairly high concentrations are reached, as is of course to be expected. It was thought that the behavior of the concentrated mixed solutions might throw some light on the question of concentrated solutions in general, and a few measurements were therefore made. While this part of the work has merely been begun, the results are of sufficient interest for a brief discussion. It was pointed out in the earlier papers that the point at which these formates begin to deviate from the mass law is not the same for any of the salts investigated. While it is of course impossible to determine exactly what that point is, it may be stated that, for example, the lithium formate solutions begin to deviate from the law at a concentration in the neighborhood of $0.25 \mathrm{~N}$; with potassium formate, on the other hand, deviation commences only above $0.40 \mathrm{~N}$. It seemed therefore that some information might be obtained by determining approximately the concentration at which a mixture of these two salts would begin to show a similar deviation. For this purpose the last 4 measurements found in Table VI were made and for a discussion of the results Table VII, containing measurements taken from Tables III and VI and calculations based upon them, was constructed. Col. I of Table VII gives the number of the measurement from III or VI, the symbol $\mathrm{Li}$ indicating that lithium salt alone is present, the symbol $\mathrm{Li}-\mathrm{K}$ that the measurement is for a mixture. Col. 2 gives the total concentration of salt dissolved; Col. 3 that of the undissociated lithium formate; Col. 4 that of the lithium ions; Col. 5 that of the undissociated potassium formate; Col. 6 that of the potassium ion; Col. 7 that of the formate ion, Col. 8 the total concentration of undissociated molecules; Col. 9 the total concentration of ions; Col. Io the concentration of all molecular species, $i . e$. , ions and undissociated molecules; and Col. I I gives the percentage deviation of the specific conductivity of each solution from the demands of the mass law.

\footnotetext{
1 Schlesinger and Martin, Loc. cit.
} 


\begin{tabular}{|c|c|c|c|c|c|c|c|c|c|c|}
\hline Expt. & $\begin{array}{l}\text { Total } \\
\text { conc. }\end{array}$ & $\begin{array}{l}\text { Conc } \\
\text { HCoOLi } \\
\text { undis. }\end{array}$ & $\begin{array}{c}\text { Conc. } \\
\text { Lition. }\end{array}$ & $\begin{array}{l}\text { Conc. } \\
\text { HCoOK } \\
\text { undis. }\end{array}$ & $\begin{array}{l}\text { Conc. } \\
\mathrm{K}+\text { ion. }\end{array}$ & $\begin{array}{l}\text { Cone. } \\
\text { HCoO- } \\
\text { ion. }\end{array}$ & $\begin{array}{l}\text { Total } \\
\text { conc. } \\
\text { inols. }\end{array}$ & $\begin{array}{l}\text { Total } \\
\text { conc. } \\
\text { ions. }\end{array}$ & $\begin{array}{l}\text { Conc. } \\
\text { mols }+ \\
\text { ions. }\end{array}$ & $\%$ dev. \\
\hline $5 \mathrm{Li}-\mathrm{K}$ & 0.2445 & 50.0197 & 0.0554 & 0.0261 & 0.1433 & 0.1987 & 0.0458 & 0.3974 & 0.4432 & 0.00 \\
\hline $32 \mathrm{Li} \ldots$ & 0.2480 & 0.0620 & 0.1860 & $\cdots$ & $\ldots$ & 0.1860 & 0.0620 & 0.3720 & 0.4340 & -0.03 \\
\hline $33 \mathrm{Li} \ldots$ & 0.2596 & 0.0670 & 0.1926 & $\ldots$ & & 0.1926 & 0.0670 & 0.3852 & 0.4522 & -0.16 \\
\hline $4 \mathrm{Li}-\mathrm{K}$ & 0.269 .3 & 0.0596 & 0.1635 & 0.0073 & 0.0389 & 0.2024 & 0.0669 & 0.4048 & 0.4717 & -0.05 \\
\hline I $3 \mathrm{Li}-\mathrm{K}$. & 0.2940 & 0.0632 & 0.1609 & 0.0117 & 0.0582 & 0.2191 & 0.0749 & 0.4382 & 0.5831 & $-0.3 I$ \\
\hline $9 \mathrm{Li}-\mathrm{K}$. & 0.3033 & 0.0474 & $0.1 I_{44}$ & 0.0248 & 0.1167 & $0.23 \mathrm{II}$ & 0.0722 & 0.4622 & 0.5344 & -0.05 \\
\hline $14 \mathrm{Ii} \ldots$ & 0.3076 & 0.0880 & 0.2196 & & 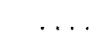 & 0.2196 & 0.0880 & 0.4392 & 0.5272 & -0.30 \\
\hline I I $\mathrm{Li}-\mathrm{K}$. & 0,3189 & 0.0673 & 0.1593 & 0.0165 & 0.0758 & $0.235 \mathrm{I}$ & 0.0838 & 0.4702 & 0.5540 & -0.32 \\
\hline${ }_{14} \mathrm{Li}-\mathrm{K} \ldots$ & 0.3430 & 0.0627 & 0.1375 & 0.0270 & o. 1558 & 0.2533 & 0.0897 & 0.5066 & 0.5963 & -0.46 \\
\hline $12 \mathrm{Li}-\mathrm{K}$. & 0.3621 & 0.0717 & 0.1516 & $0.027 I$ & $0.1 I I 7$ & 0.2633 & 0.0988 & 0.5266 & 0.6254 & -0.62 \\
\hline
\end{tabular}

It will be seen from the table that the total concentration of dissolved substance is not the factor which determines when deviation begins. Nor is it the total amount of either salt, for when lithium formate is alone present the concentration of the first solution which shows decided deviation is 0.2596 ; in the mixtures, however, a solution containing only 0.224 moles (i.e., 0.0632 moles of undissociated and 0.1609 moles of dissociated lithium salt) of lithium formate is already deviating. On the other hand, a solution containing in a mixture almost the same amount of this salt, namely 0.223 moles per liter (i.e., 0.0596 moles of undissociated and 0.1635 moles of dissociated lithium salt) does not deviate. If now the various data given in Table VII are examined in this way it will be seen that of all the various factors included, only the concentration of the undissociated lithium formate shows any parallelism with the deviations of the concentrated solutions. Thus, it seems that no matter whether there is potassium formate present or not, no matter what the total number of molecules or of ions, no matter what the number of the 3 kinds of ions present, deviation from the mass law occurs when the wider concentration of the undissociated lithium formate is above $0.062 .{ }^{1}$ We may therefore tentatively conclude that in the more concentrated solutions the deviation is essentially due to a deviation from the mass law in the behavior of the undissociated molecules, or at least due to some factor which is proportional to the concentration of the undissociated molecules. ${ }^{2}$

\section{Solutions Containing Either One Uni-univalent and One Uni-bivalent or Two Uni-bivalent Formates.}

In an earlier paper of this series, ${ }^{3}$ the peculiar behavior of the formates of the alkaline earth metals was pointed out. These salts, although they are uni-bivalent, appear to be judged by the conductivities of their

${ }^{2}$ Any deviation less than $0.1 \%$ is considered due to experimental error.

2 It should be noted that in the concentrated solutions the conductivity, and therefore the degree of ionization, are smaller that demanded by the mass laws.

s Schlesinger and Mullinix, Loc cit. 
solutions, to obey the mass law as derived for uni-univalent salts within a range of concentration from about 0.1 to 0.35 equivalent. Above the upper limit named they behave in the manner characteristic of the behavior of the alkali metal formates; ${ }^{1}$ below the lower limit, however, there is a deviation which corresponds to a greater ionization than is to be expected from the law obeyed in the middle range of concentration. It was pointed out that the behavior of these salts might be taken to indicate that they ionize in moderate concentrations into two ions onlyi.e., into formate and an alkali metal formate ion-and that only in quite dilute solutions does ionization into the simple ions take place. There were, however, reasons for doubting the correctness of this conclusion, and it was therefore also suggested that the apparent agreement with the law for uni-univalent salts in the moderate concentrations might be due to a cancellation of two deviations in opposite directions-namely the deviation noted in concentrated and that noted in dilute solutions. In order to gain further light on this question the behavior of mixtures containing these salts was studied.

In calculating the conductivities which would be exhibited by mixtures, for example, of potassium and strontium formates from the constants given in this paper and the preceding one of this series a number of points must be borne in mind. Let us assume, first, that both salts ionize into two ions only. In this case the ionization constant for the strontium salt given by Schlesinger and Mullinix ${ }^{2}$ cannot be directly used in the equations developed above for the calculation of the value of the conductivities of the mixed solutions from the ionization constants, since in calculating the constant for strontium formate the concentrations were expressed in gram equivalents per liter. For use in the mass law the concentrations should be in moles. By following out the line of reasoning employed in deriving the equations for the mixtures containing only uni-univalent salts in the case now under consideration, it can be shown that the same equations can be used, if instead of using the constant given by Schlesinger and Mullinix we divide this constant by two and express the concentrations of the strontium salt in terms of gram equivalents. It is possible, however, to make another assumption with regard to the mode of ionization of the strontium salt, namely, that it breaks up into strontium ion and two formate ions but that it nevertheless follows the equation of the mass law which is applicable when there are only two ions formed. The calculation of the conductivities of the mixtures of potassium and strontium formates on this assumption can be shown to be exactly like the calculations made for the mixtures containing only alkali metal formates, provided the ionization constant for

${ }^{1}$ See the second paper of the series, Loc. cit.

${ }^{2}$ Loc. cit. 
the strontium salt as given by Schlesinger and Mullinix is used and the concentrations are again expressed in gram equivalents per liter. In order to make the calculations on each of these assumptions, two sets of values for $\alpha_{1}$ had to be calculated and two plots had to be made. The values calculated for the first assumption are called $\alpha_{1, \mathrm{Sr}}^{\prime}$ in Table IV and those for the second assumption, $\alpha_{1, \mathrm{Sr}}^{\prime \prime}$. The comparison of the calculated value for the conductivity of the mixtures with the value found by experiment is made in Tables VIII $a$ and VIII $b$. Table VIII $a$ contains the data for the calculation on the basis of the first assumption and VIII $b$ those for the calculation on the second assumption. Inspection of the tables shows that neither of the calculated values agrees at all with the conductivities found. In order to make sure that this result is not due to an error in the value of the constant for the strontium formate or to some other cause peculiar to the strontium salt, the conductivites of a few mixtures of potassium formate and calcium formate were measured, but as the results were exactly similar to those with the strontium salts they have not been included. In Table IX data and calculations for mixtures of calcium and strontium formates are given. It can be shown that the method of calculation to be used for this case is the same as that used for mixtures of uni-univalent salts on either of the TABle VIII.-The Conductivity of Solutions of Mixtures of Strontium and Potassium Formates in ANHYdrous Formic ACID at $25^{\circ}$.

\section{TABLE VIII $a$.}

\begin{tabular}{llllllll}
\multicolumn{1}{c}{$C_{s .}$} & \multicolumn{1}{c}{$C_{1 .}$} & \multicolumn{1}{c}{$C_{2 .}$} & $\alpha_{1 .}$ & $\alpha_{2 .}$ & \multicolumn{1}{c}{ x calc. ${ }^{d}$} & X found. & $\%$ dev. \\
0.09193 & 0.06565 & 0.06536 & 0.751 & 0.927 & 0.006973 & 0.007043 & 1.0 \\
0.1042 & 0.07530 & 0.07433 & 0.728 & 0.919 & 0.007818 & 0.007939 & 1.5 \\
0.1172 & 0.1224 & 0.06969 & 0.706 & 0.911 & 0.009278 & 0.009413 & 1.5 \\
0.1225 & 0.09025 & 0.08777 & 0.698 & 0.908 & 0.009062 & 0.009140 & 0.9 \\
0.1339 & 0.2526 & 0.03843 & 0.681 & 0.900 & 0.01213 & 0.01229 & 1.3 \\
0.1554 & 0.06337 & 0.1322 & 0.651 & 0.888 & 0.01042 & 0.01057 & 1.5 \\
0.1555 & 0.1580 & 0.09763 & 0.650 & 0.888 & 0.01180 & 0.01200 & 1.7 \\
0.1604 & 0.1162 & 0.1181 & 0.644 & 0.885 & 0.01145 & 0.01166 & 1.8 \\
0.2348 & 0.1947 & 0.1699 & 0.564 & 0.846 & 0.01613 & 0.01652 & 2.4
\end{tabular}

$\begin{array}{llllllll}0.1248 & 0.06565 & 0.06536 & 0.820 & 0.906 & 0.007134 & 0.007043 & 1.3 \\ 0.1417 & 0.07530 & 0.07433 & 0.802 & 0.896 & 0.008013 & 0.007939 & 0.9 \\ 0.1674 & 0.09025 & 0.08777 & 0.777 & 0.881 & 0.009305 & 0.009140 & 1.8 \\ 0.1771 & 0.1224 & 0.06969 & 0.768 & 0.875 & 0.009538 & 0.009413 & 1.3 \\ 0.1875 & 0.06337 & 0.1322 & 0.759 & 0.870 & 0.01065 & 0.01057 & 0.7 \\ 0.2179 & 0.1162 & 0.1181 & 0.734 & 0.854 & 0.01178 & 0.01166 & 1.1 \\ 0.2325 & 0.1580 & 0.09763 & 0.723 & 0.847 & 0.01217 & 0.01200 & 1.4 \\ 0.2521 & 0.2526 & 0.03843 & 0.709 & 0.838 & 0.01234 & 0.01229 & 0.6 \\ 0.3296 & 0.1947 & 0.1699 & 0.661 & 0.805 & 0.01673 & 0.01652 & 1.3\end{array}$

a The values of the equivalent conductivity and infinite dilution used in obtaining these values of $\mathrm{X}_{\mathrm{catc}}$, are 68.92 and 55.72 for the potassium and the strontium formate, respectivelv. 
two assumptions made above and that the concentrations may for either case be expressed in equivalents, as was done in the original paper of Schlesinger and Mullinix, and that the values of the constants given by them are to be employed. The "second" salt of the mixture, that of higher degree of ionization, is in this case strontium formate and the subscript $\mathrm{I}$ therefore refers to the calcium and the subscript 2 to the strontium salt. The calculated values again fail to agree with the experimental ones. It is clear that neither of the assumptions made above represents correctly the behavior of these salts. It is likely, therefore, that both modes of ionization occur-i.e., into intermediate ions and into the simple ions, but this point is not yet considered established. ${ }^{1}$

TABLE IX.-The Conductivity of Solutions of Mixtures of Calcium and Strontium Formates in ANHYdrous Formic ACID at $25^{\circ}$.

\begin{tabular}{|c|c|c|c|c|c|c|c|c|}
\hline & $C_{s}$. & $C_{t}$. & $C_{2}$ & $\boldsymbol{\alpha}_{\mathbf{1}}$ & $\alpha_{2}$ & & $\mathrm{x}$ found. & 7 \\
\hline & 0.1343 & .06482 & .07183 & .793 & .823 & 0.006177 & 0.006 I 39 & $0.6 \mathrm{I}$ \\
\hline & 0.1727 & .08953 & & & .790 & & & \\
\hline & 1905 & 09815 & & & & & & \\
\hline $3 \ldots \ldots \ldots$ & & & & & & & & \\
\hline$\ldots \ldots \ldots$ & .2258 & & & & & & & $\cdot 3$ \\
\hline & .2802 & .1494 & & 7 & 0.718 & 24 & & .45 \\
\hline & $.282 \mathrm{I}$ & 0.1485 & & & .717 & & & .42 \\
\hline & 0.2892 & & & & & & & .4 \\
\hline & & & & & & & & 4 \\
\hline & & & & & & & & 4 \\
\hline & $0.344 \mathrm{I}$ & & & & & & & \\
\hline & 0.3714 & 0.1950 & 0.1893 & 0.628 & 0.673 & 0.01395 & 0.01386 & \\
\hline
\end{tabular}

a The value used for the equivalent conductivity of calcium formate at infinite dilution is 54.94. For strontium formate that given for Table IX was used.

\section{Summary.}

I. A method of calculating from the ionization constants the degree of ionization of each of two salts containing a common ion, when the two salts are both present in solution, has been developed for the case in which both salts obey the mass law.

2. It has been found that in solutions of mixtures of sodium and potassium formates, as well as of lithium and potassium formates, the mass law is obeyed by both of the highly ionized salts present. On the other hand, solutions of mixtures containing as one, or as both of the salts, alkaline earth formates do not conform to the law, although these unibivalent salts when in solution alone seem to follow the law over a certain range of concentration. This seems to make it quite certain that whenever the agreement of the salt with the law is merely an accidental one, solutions of mixtures containing such a salt will not obey this law. Hence we may conclude quite definitely that the agreement between the behavior of the

${ }^{1}$ Further evidence is presented in the seventh paper of this series, which follows. 
alkaline metal formates, in anhydrous formic acid solutions, and the demands of the mass law is a real, and not an accidental one.

3. As is to be expected, when the total concentration of mixed solutions becomes relatively great, deviation from the mass law occurs also in the solutions which contain only uni-univalent formates. It has been found that this deviation seems to begin when the concentration of the undissociated molecules of one of the salts reaches the same value as that at which deviation begins in the solution of that salt by itself. This seems to be independent of the concentration of the other molecular species present and to indicate that in the concentrated solutions it is the undissociated molecules and not the ions which cause deviation from the mass law or at least that the undissociated molecules cause deviation at lower concentrations than do the ions. ${ }^{1}$

ChrCago, Ihi.

[CONTRIBUTION FROM THE KENT CHEMICAL LABORATORY OF THE UNIVERSITY OF Chicago.]

\section{STUDIES IN CONDUCTIVITY. VII. TRANSFERENCE NUMBERS OF THE FORMATES OF SODIUM, POTASSIUM AND CALCIUM IN ANHYDROUS FORMIC ACID.}

By H. I. SCHLESINGER AND E. N. BUNTING. ${ }^{2}$

Received July 28, 1919.

The work of the preceding papers of this series, ${ }^{3}$ particulary that of the sixth one, has proved that the agreement in the behavior of the formates of the alkali metals, when dissolved in formic acid, with the demands of the mass law, is a real and not an accidental one so far as it is possible to establish this conclusion by the use of conductivity data alone. The only weakness in the argument lies in the fact that from the conductivity data two constants mist be calculated for each salt-the ionization constant and the conductivity at infinite dilution, the latter of which must be obtained by extrapolation. If, however, we assume that the conductivity at infinite dilution obtained in this way for one of the salts is correct, we can calculate from this value and the transference numbers of this and the other salts the conductivity at infinite dilution for those

${ }^{1}$ It must be recalled that the deviation herein referred to is of a different type from that commonly known in moderately dilute aqueous solutions of strong electrolytes (see the second paper of the series) in which the undissociated molecules are likewise frequently believed to be the deviating species.

2 The work herein reported has been presented to the Faculty of the Ogden Graduate School of Science of the University of Chicago by E. N. Bunting in partial fulfillment of the requirements for the degree of Doctor of Philosophy. The work was completed in the summer of 1918 .

8 Schlesinger and collaborators, This Journal, 33, I924 (I9I I); 36, I589 (I9I4); 38,271 (1916); 41, 72, 1727, 1921 (1919). 